\title{
Pengaruh Temperatur Sintesis Hidrotermal Terhadap Diameter Nanopartikel Seng Oksida
}

\author{
Adine Melossa Famia*, Muldarisnur \\ Laboratorium Fisika Material, Jurusan Fisika \\ Fakultas Matematika dan Ilmu Pengetahuan Alam Universitas Andalas \\ Kampus Unand Limau Manis, Padang, 25163 Indonesia \\ *adinemelossafamia@gmail.com
}

\begin{abstract}
ABSTRAK
Pengaruh temperatur terhadap diameter nanopartikel seng oksida $(\mathrm{ZnO})$ yang disintesis dengan metode hidrotermal telah diteliti. Temperatur divariasikan sebesar $70{ }^{\circ} \mathrm{C}, 80{ }^{\circ} \mathrm{C}, 90{ }^{\circ} \mathrm{C}, 100{ }^{\circ} \mathrm{C}$, dan $110{ }^{\circ} \mathrm{C}$. Nanopartikel $\mathrm{ZnO}$ dikarakterisasi dengan Scanning Electron Microscope untuk mengamati morfologi permukaan dan menentukan ukuran partikel. XRD digunakan untuk mengetahui struktur dan ukuran kristal. Temperatur mempengaruhi ukuran partikel setiap sampel dengan diameter yaitu, 76,72; 95,32; 170,72; 100,37; dan 54,27 nm. Ukuran kristal semua sampel berturut-turut adalah 42.07; 52.7; 52.7; 52.7; dan $42.07 \mathrm{~nm}$. Diameter partikel dan ukuran kristal dipengaruhi oleh temperatur sintesis, dimana semakin tinggi temperatur sintesis, semakin kecil diameter partikel dan ukuran kristal $\mathrm{ZnO}$ yang terbentuk. Nanorod terbentuk pada temperatur $80^{\circ} \mathrm{C}$ dengan aspek rasio sebesar 1,7 .

Kata kunci: nanopartikel, temperatur, seng oksida $(\mathrm{ZnO})$, hidrotermal
\end{abstract}

\begin{abstract}
Effect of hydrothermal synthesis temperature on the diameter of synthesized zinc oxide (zno) has been investigation. Synthesis were carried at $70{ }^{\circ} \mathrm{C}, 80{ }^{\circ} \mathrm{C}, 90{ }^{\circ} \mathrm{C}, 100{ }^{\circ} \mathrm{C}$, and $110{ }^{\circ} \mathrm{C}$. Zinc oxide nanoparticle were characterized using sem to observe surface morphology and particle size and xrd was is determine crystal structure and size. Temperature effects in particle size which are 76,72, 95,32, 170,72, 100,37, dan 54,27 nm. Crystal size of zno particles are consecutively 42.07, 52.7, 52.7, 52.7, and $42.07 \mathrm{~nm}$. Crytsal structure in all sample are hexagonal shape. Particle diameter and crystal size depend on synthesis temperature, where the increase at synthesis temperature decrease particle diameter and crystal size. Nanorods was formed at temperature $80^{\circ} \mathrm{c}$ with aspect ratio 1.7.

Keywords: nanoparticles, temperature, zinc oxide ( $\mathrm{ZnO})$, hydrothermal
\end{abstract}

\section{PENDAHULUAN}

Salah satu bidang nanoteknologi yang banyak diteliti adalah sintesis dan aplikasi nanopartikel. Nanopartikel didefinisikan sebagai padatan berukuran antara $1-100 \mathrm{~nm}$. Nanopartikel memiliki sifat listrik, optik, magnetik, dan mekanik yang lebih unggul dibandingkan dengan material berukuran besar (bulk). Sifat-sifat tersebut bergantung pada ukuran, bentuk, kemurniaan, permukaan, maupun topologi material.

Nanopartikel dapat memiliki beberapa bentuk geometri seperti bulat (nanosphere), batang (nanorod), lembaran (nanosheet), tabung (nanotube), dan kawat (nanowire). Nanorod merupakan struktur nano berbentuk silinder pejal dengan diameter kurang dari $100 \mathrm{~nm}$. Nanorod memiliki konduktivitas elektron lebih tinggi dibandingkan dengan bentuk geometri lain karena transpor elektron yang bersifat balistik, tidak terjadi hamburan elektron (Yuwono dan Dharma, 2011). Nanorod banyak diaplikasikan pada sel surya berbasis DSSC karena dapat meningkatkan absorbsi cahaya. Nanorod juga diaplikasi pada bidang optik, elektronik, piezoelektrik, dan sensor (Sholehah, 2015).

Seng oksida $(\mathrm{ZnO})$ adalah material yang memiliki banyak aplikasi, antara lain pada sel surya, laser dioda, Light Emitting Diode (LED), fotovoltaik, piranti elektroluminisensi, dan optoelektronika. ZnO bersifat transparan terhadap cahaya tampak, memiliki mobilitas elektron yang tinggi, memiliki bandgap yang lebar, tahan pada temperatur tinggi, dan merupakan penyerap sinar UV yang sangat baik.

Metode hidrotermal memungkinkan sintesis pada temperatur rendah (dibawah $150{ }^{\circ} \mathrm{C}$ ) dan dengan peralatan sederhana. Proses hidrotermal memungkinkan pengontrolan ukuran kristal, morfologi, dan tingkat aglomerasi dengan pemilihan bahan baku, keasaman $(\mathrm{pH})$, waktu, dan suhu. Diameter dan panjang nanorod $\mathrm{ZnO}$ dipengaruhi oleh temperatur (Stein, 2009). Metode hidrotermal menghasilkan nanorod $\mathrm{ZnO}$ dengan kristalinitas yang lebih baik 
dibandingkan dengan metode sol-gel. Romero dan Garcia (2013), mensintesis nanorod ZnO dengan metode hidrotermal menggunakan prekursor hexamethylenetetramine (HMTA), surfaktan methenamine, dan katalis zinc nitrate. Pada penelitian tersebut nanorod $\mathrm{ZnO}$ disintesis dengan metode hidrotermal pada temperatur konstan $90{ }^{\circ} \mathrm{C}$ dan waktu tahan dua jam. Diameter dan panjang $\mathrm{ZnO}$ nanorod yang terbentuk sebesar $400 \mathrm{~nm}$ dan $4 \mu \mathrm{m}$.

Pada penelitian ini akan disintesis $\mathrm{ZnO}$ nanorod menggunakan metode hidrotermal dengan memvariasikan temperatur sintesis. $\mathrm{ZnO}$ yang disintesis akan dikarakterisasi menggunakan Scanning Electron Microscope (SEM) dan X-Ray Diffraction (XRD).

\section{METODE}

\subsection{Alat dan Bahan}

Alat yang digunakan untuk pembuatan nanopartikel $\mathrm{ZnO}$ yaitu gelas ukur, spatula, timbangan digital, magnetic stirrer, oven, furnace, autoclave, X-Ray Diffraction, dan Scanning Electron Microscopy. Bahan yang digunakan aquades, Hexamethylenetetramine $\left[\left(\mathrm{CH}_{3}\right)_{6} \mathrm{Na}_{4}\right]$, Zincnitrat $\left.\left[\mathrm{Zn}\left(\mathrm{NO}_{3}\right)_{2} \cdot 6 \mathrm{H}_{2} \mathrm{O}\right)\right]$, dan Methenamine $\left(\mathrm{C}_{6} \mathrm{H}_{12} \mathrm{~N}_{4}\right)$.

\subsection{Teknik Penelitian}

Bahan yang digunakan untuk pembuatan $\mathrm{ZnO}$ adalah prekursor dan surfaktan. Larutan prekursor dibuat dari zincnitrat dan surfaktan menggunakan hexamethylenetetramine (Romero dan Garcia, 2013). Sehingga, nanopartikel $\mathrm{ZnO}$ terbentuk didapatkan dari persamaan kimia sebagai berikut :

$$
\begin{aligned}
& \mathrm{Zn}\left(\mathrm{NO}_{3}\right)_{2}+2 \mathrm{H}_{2} \mathrm{O} \\
& \mathrm{Zn}(\mathrm{OH})_{2} \\
& \mathrm{Zn}(\mathrm{OH})_{2}+2 \mathrm{OH}- \\
& {\left[\mathrm{Zn}(\mathrm{OH})_{4}\right]^{2-}} \\
& \mathrm{Zn}^{2+}+2 \mathrm{OH} \\
& \mathrm{Zn}\left(\mathrm{NO}_{3}\right)_{2}+2 \mathrm{H}_{2} \mathrm{O}
\end{aligned}
$$

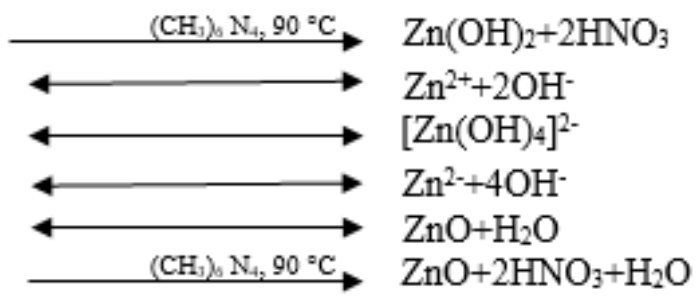

\subsubsection{Sintesis Nanorod Seng Oksida ( $\mathrm{ZnO})$}

Nanorod $\mathrm{ZnO}$ disintesis menggunakan prosedur yang dikembangkan oleh Romero dan Garcia (2013). Zincnitrat dan methenamine masing-masing sebanyak $1 \mathrm{~g}$ dilarutkan dengan pelarut aquades dan diaduk menggunakan magnetic stirrer di gelas ukur dengan temperatur 50 ${ }^{\circ} \mathrm{C}$ dengan kecepatan $3 \mathrm{rpm}$ selama satu jam. Kemudian $0,75 \mathrm{~g}$ hexamethylenetetramine ditambahkan ke dalam gelas ukur yang berisi larutan zincnitrat dan methenamine. Larutan diletakkan dalam teflon kemudian dimasukkan ke dalam autoclave dan dipanaskan dengan menggunakan variasi temperatur yaitu: $70{ }^{\circ} \mathrm{C}, 80{ }^{\circ} \mathrm{C}, 90{ }^{\circ} \mathrm{C}, 100{ }^{\circ} \mathrm{C}$, dan $110{ }^{\circ} \mathrm{C}$ selama dua puluh jam menggunakan oven. Selanjutnya larutan didinginkan pada temperatur ruang. Setelah pendinginan selesai, sampel dipindahkan ke magnetic strirrer dan dipanaskan pada suhu 100 ${ }^{\circ} \mathrm{C}$. Setelah itu, larutan dimasukkan ke dalam furnace dengan suhu $600{ }^{\circ} \mathrm{C}$ selama empat jam, sehingga sampel berbentuk serbuk.

\subsubsection{Karakterisasi Seng Oksida $(\mathrm{ZnO})$}

Morfologi dan ukuran dari seng oksida yang terbentuk dikarakterisasi menggunakan SEM (Scanning Electron Microscope). Ukuran partikel $\mathrm{ZnO}$ diukur dari citra SEM menggunakan aplikasi ImageJ.

Kemurnian seng oksida yang terbentuk dikarakterisasi menggunakan XRD. Data XRD berupa difraktogram dianalisis dan dibandingkan dengan data pola difraksi ICDD (International Center for Diffraction Database) dalam file Powder Diffraction File (PDF). Grafik puncakpuncak tertinggi setiap sampel dianalisis menggunakan aplikasi Origin 8.5.1. Ukuran kristal dari sampel $\mathrm{ZnO}$ akan dihitung dari difraktogram dengan menggunakan persamaan Scherrer yaitu :

$$
D=\frac{k \lambda}{B \cos \theta}
$$


dimana D adalah ukuran kristal, $K$ adalah nilai konstanta bentuk partikel $(0,9), \lambda$ adalah panjang gelombang radiasi sinar-x, $B$ adalah lebar penuh garis difraksi pada saat intensitas setengah maksimum, dan $\theta$ adalah sudut Bragg.

\section{HASIL DAN DISKUSI}

\subsection{Morfologi dan Geometri Nanopartikel}

Pengaruh temperatur hidrotermal terhadap bentuk geometri serta ukuran nanopartikel ditentukan menggunakan SEM dengan perbesaran SEM $40.000 \times$. Gambar 1 merupakan hasil SEM ZnO yang disintesis pada temperatur $70{ }^{\circ} \mathrm{C}, 80^{\circ} \mathrm{C}, 90^{\circ} \mathrm{C}, 100{ }^{\circ} \mathrm{C}$, dan $110{ }^{\circ} \mathrm{C}$. $\mathrm{ZnO}$ yang disintesis pada temperatur $70{ }^{\circ} \mathrm{C}$ memperlihatkan partikel yang menggumpal. Aglomerasi terjadi karena koloid $\mathrm{ZnO}$ cenderung mudah menggumpal pada suhu rendah, sehingga ukuran partikel cenderung menjadi tidak seragam pada suhu rendah. Aglomerasi cenderung berkurang ketika $\mathrm{ZnO}$ disintesis pada temperatur $80{ }^{\circ} \mathrm{C}, 90^{\circ} \mathrm{C}$, dan $100{ }^{\circ} \mathrm{C}$. Permukaan sampel yang disintesis pada temperatur $80{ }^{\circ} \mathrm{C}-100{ }^{\circ} \mathrm{C}$ terlihat homogen serta ukuran partikel pada permukaan lebih seragam. Gambar 2 memperkuat pernyataan bahwa sampel yang disintesis pada temperatur $80{ }^{\circ} \mathrm{C}$ partikel $\mathrm{ZnO}$ memiliki permukaan yang lebih homogen. Hal ini terlihat dari standar deviasi ukuran partikel pada temperatur $80^{\circ} \mathrm{C}$ lebih rendah daripada sampel lain. Pada sampel dengan temperatur $110{ }^{\circ} \mathrm{C}$ partikel $\mathrm{ZnO}$ yang terbentuk menggumpal dan tidak homogen. Pada temperatur tinggi (diatas $100^{\circ} \mathrm{C}$ ) uap-uap yang terkumpul di dalam autoclave akan memberikan tekanan yang terlalu besar sehingga dapat menghambat pertumbuhan partikel $\mathrm{ZnO}$ (Stein, 2009).

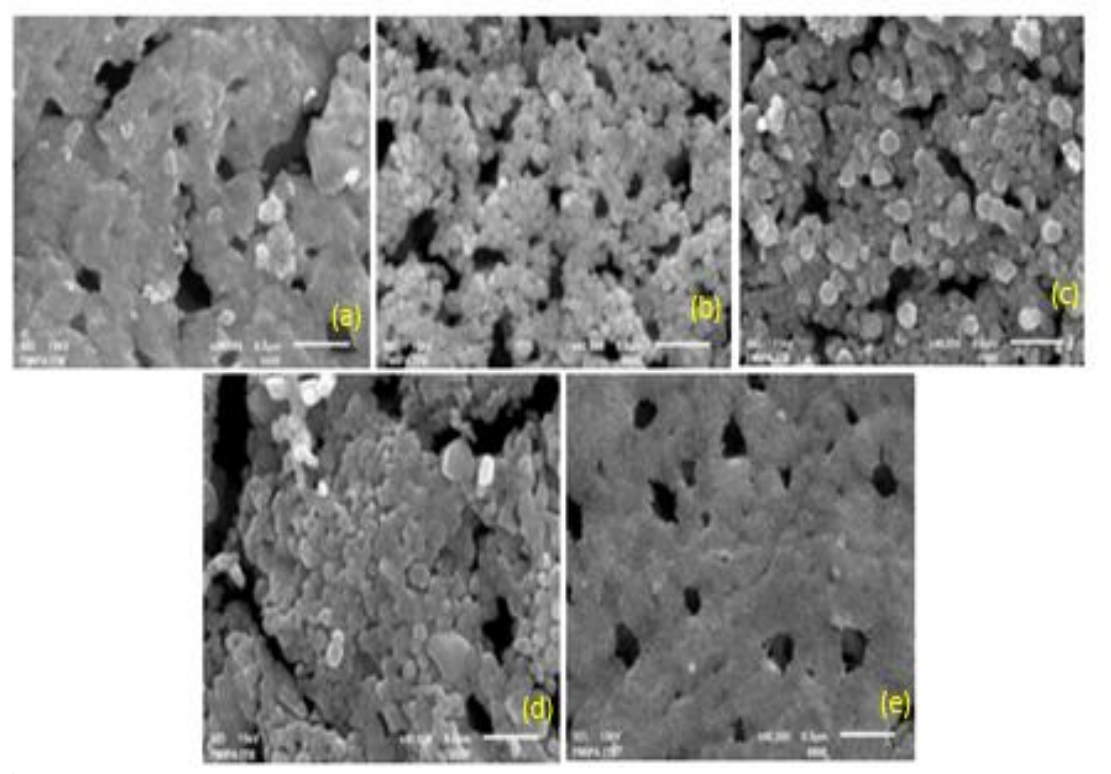

Gambar 1 SEM ZnO yang disintesis pada temperatur (a) $70{ }^{\circ} \mathrm{C}$, (b) $80{ }^{\circ} \mathrm{C}$, (c) $90{ }^{\circ} \mathrm{C}$, (d) $100{ }^{\circ} \mathrm{C}$, dan (e) $110^{\circ} \mathrm{C}$ 


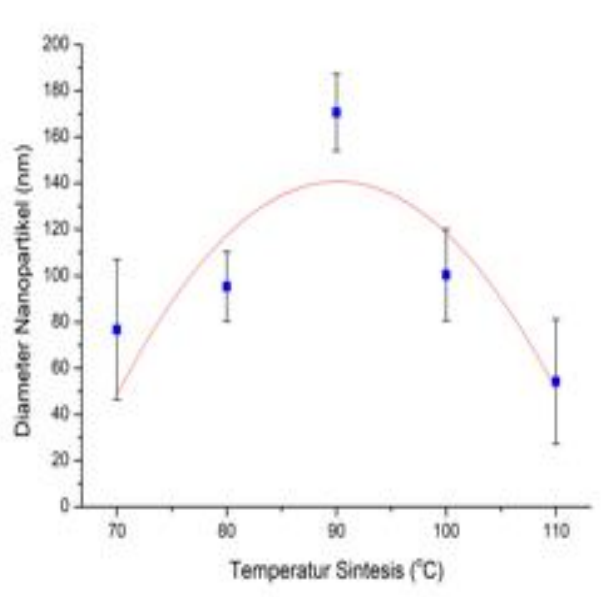

(a)

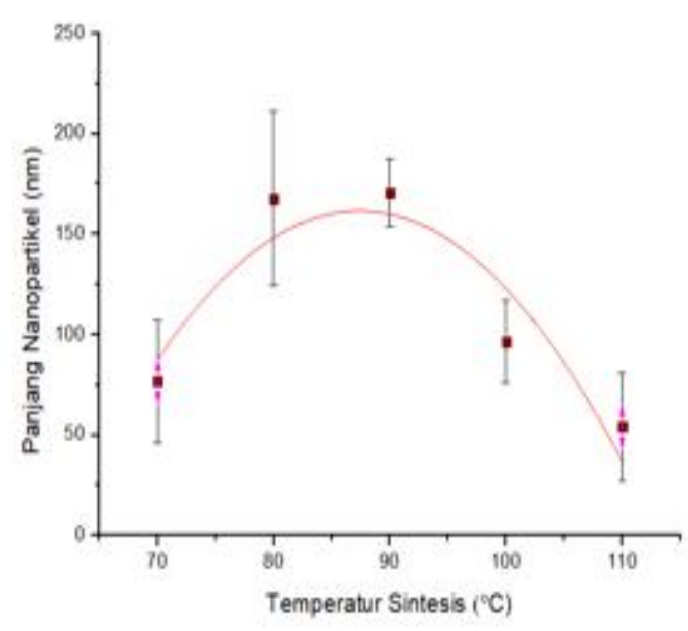

(b)

Gambar 2 (a) Grafik pengaruh temperatur sintesis terhadap diameter nanopartikel ZnO yang terbentuk dan (b) Grafik pengaruh temperatur sintesis terhadap panjang nanopartikel $\mathrm{ZnO}$ yang terbentuk

Gambar 2 (a) menunjukkan pengaruh temperatur terhadap diameter partikel $\mathrm{ZnO}$. Diameter rata-rata untuk $\mathrm{ZnO}$ dengan temperatur $70{ }^{\circ} \mathrm{C}$ sebesar $(76,7 \pm 30,4) \mathrm{nm}$. Pada temperatur $80{ }^{\circ} \mathrm{C}$ dan $90{ }^{\circ} \mathrm{C}$ diameter rata $\mathrm{ZnO}$ mengalami peningkatan menjadi $(95,3 \pm 15,1)$ $\mathrm{nm}$ dan $(170,7 \pm 16,7) \mathrm{nm}$. Diameter rata-rata partikel $\mathrm{ZnO}$ yang disintesis pada suhu diatas 90 ${ }^{\circ} \mathrm{C}$ kembali berkurang menjadi $(100,4 \pm 19,8) \mathrm{nm}$ dan $(54,3 \pm 26,9) \mathrm{nm}$. Diameter $\mathrm{ZnO}$ mengalami penurunan yang signifikan pada temperatur $110^{\circ} \mathrm{C}$. Hal ini disebabkan temperatur yang digunakan tinggi sehingga mempengaruhi diameter $\mathrm{ZnO}$ temperatur $110{ }^{\circ} \mathrm{C}$ menjadi tidak stabil. Menurut Stein (2009), diameter partikel $\mathrm{ZnO}$ dipengaruhi oleh temperatur sintesis dan tekanan. Gambar 2 (b) menunjukkan $\mathrm{ZnO}$ yang bertemperatur $80{ }^{\circ} \mathrm{C}$ dan $100{ }^{\circ} \mathrm{C}$ memiliki panjang rata-rata $(164,7 \pm 43,4) \mathrm{nm}$ dan $(96,7 \pm 20,6) \mathrm{nm}$. Untuk $\mathrm{ZnO}$ dengan temperatur 70 ${ }^{\circ} \mathrm{C}, 90{ }^{\circ} \mathrm{C}$, dan $110{ }^{\circ} \mathrm{C}$ panjang rata-ratanya adalah $(76,7 \pm 30,4) \mathrm{nm},(170,7 \pm 16,7) \mathrm{nm}$, dan $(54,3 \pm 26,9) \mathrm{nm}$.

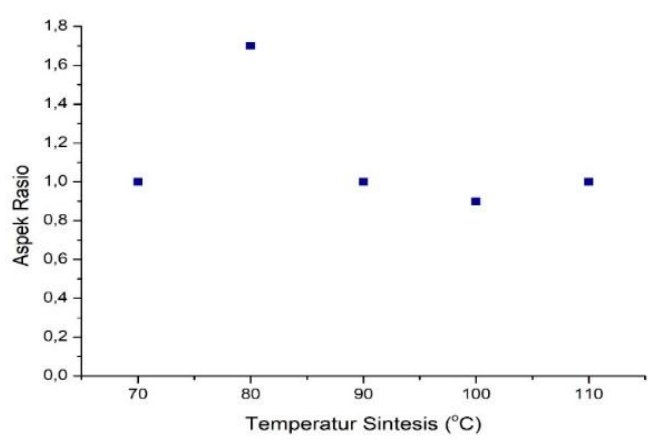

Gambar 3 Aspek rasio nanopartikel $\mathrm{ZnO}$ sebagai fungsi temperatur sintesis

Gambar 3 menunjukkan aspek rasio nanopartikel $\mathrm{ZnO}$ sebagai fungsi temperatur sintesis. Aspek rasio merupakan perbandingan panjang dengan diameter dari nanopartikel $\mathrm{ZnO}$ yang terbentuk. Aspek rasio $\mathrm{ZnO}$ dengan temperatur $70{ }^{\circ} \mathrm{C}, 90{ }^{\circ} \mathrm{C}$, dan $110{ }^{\circ} \mathrm{C}$ memiliki nilai yang sama yaitu satu. Untuk temperatur $80{ }^{\circ} \mathrm{C}$ dan $100{ }^{\circ} \mathrm{C}$ nilai aspek rasio sebesar 1,7 dan 0,9 . Pada temperatur $80{ }^{\circ} \mathrm{C} \mathrm{ZnO}$ berbentuk nanorod disebabkan aspek rasio sebesar 1,7. Untuk temperatur $70{ }^{\circ} \mathrm{C}, 90{ }^{\circ} \mathrm{C}$, dan $110{ }^{\circ} \mathrm{C} \mathrm{ZnO}$ yang terbentuk berupa nanosphere dengan aspek rasio sebesar satu dan 0,9 pada $\mathrm{ZnO}$ dengan temperatur $100{ }^{\circ} \mathrm{C}$ berbentuk bulat. 


\subsection{Struktur Kristal Nanopartikel ZnO}

XRD digunakan untuk mengetahui struktur dan ukuran kristal nanopartikel $\mathrm{ZnO}$. Difraktogram XRD menampilkan puncak-puncak difraksi informasi struktur dan ukuran kristal. Pola difraksi XRD sampel dibandingkan dengan pola difraksi standar yang dikeluarkan oleh International Center for Diffraction Database (ICDD). Gambar 4 memperlihatkan puncak difraksi XRD ZnO nanopartikel yang disintesis pada temperatur $70{ }^{\circ} \mathrm{C}, 80^{\circ} \mathrm{C}, 90{ }^{\circ} \mathrm{C}, 100{ }^{\circ} \mathrm{C}$, dan $110^{\circ} \mathrm{C}$.

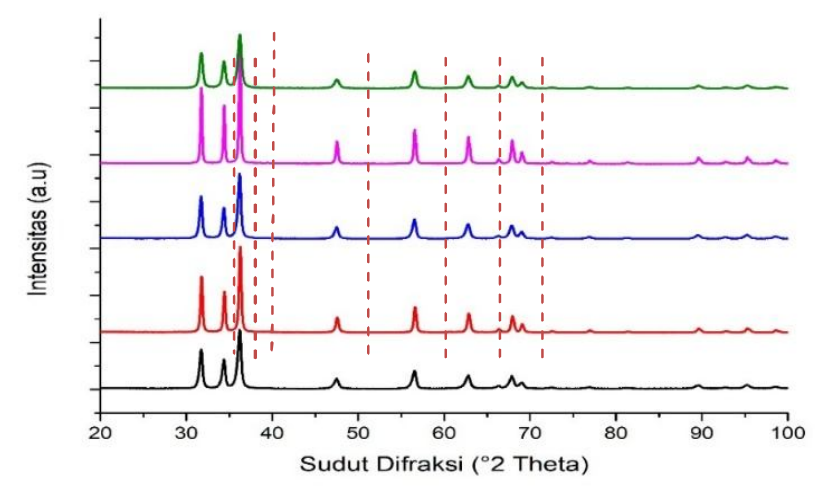

Gambar 4 Pola difraksi sinar-X nanopartikel $\mathrm{ZnO}$ yang disintesis pada temperatur $70{ }^{\circ} \mathrm{C}, 80{ }^{\circ} \mathrm{C}$, $90{ }^{\circ} \mathrm{C}, 100{ }^{\circ} \mathrm{C}$, dan $110^{\circ} \mathrm{C}$

Puncak difraksi tertinggi nanopartikel $\mathrm{ZnO}$ yang disintesis pada temperatur $70{ }^{\circ} \mathrm{C}-110$ ${ }^{\circ} \mathrm{C}$ berada pada sudut $(2 \theta)=36,2201^{\circ}, 36,2633^{\circ}, 36,2018^{\circ}, 36,2548^{\circ}$, dan $36,2217^{\circ}$. Intensitas atau tinggi puncak difraksi mengindikasikan kristalinitas nanopartikel. Semakin tinggi puncak difraksi sinar-X berarti tingkat kristalinitas nanopartikel $\mathrm{ZnO}$ lebih tinggi. Dapat dilihat pada grafik $\mathrm{ZnO}$ yang disintesis pada temperatur $100{ }^{\circ} \mathrm{C}$ memiliki puncak yang lebih tinggi daripada sampel lainnya. Menurut Sirenden (2012), semakin kecil lebar setengah puncak maksimum, maka tingkat kristalinitas nanopartikel $\mathrm{ZnO}$ lebih tinggi.

Tabel 1 Perbandingan parameter kristal $\mathrm{ZnO}$ untuk setiap sampel

\begin{tabular}{lcccccccc}
\hline Sampel & $2 \theta\left(^{\circ}\right)$ & $\begin{array}{c}\text { Sistem } \\
\text { Kristal }\end{array}$ & $A$ & $B$ & $\gamma$ & $a(\AA)$ & $b(\AA)$ & $c(\AA)$ \\
\hline ZnO 70 & 36,22 & hexagonal & $90^{\circ}$ & $90^{\circ}$ & $120^{\circ}$ & 3,2522 & 3,2522 & 5,2095 \\
ZnO 80 & 36,22 & hexagonal & $90^{\circ}$ & $90^{\circ}$ & $120^{\circ}$ & 3,2533 & 3,2533 & 5,2072 \\
$\mathrm{ZnO} \mathrm{90}$ & 36,22 & hexagonal & $90^{\circ}$ & $90^{\circ}$ & $120^{\circ}$ & 3,2568 & 3,2568 & 5,2125 \\
$\mathrm{ZnO} 100$ & 36,22 & hexagonal & $90^{\circ}$ & $90^{\circ}$ & $120^{\circ}$ & 3,2533 & 3,2533 & 5,2072 \\
$\mathrm{ZnO} \mathrm{110}$ & 36,22 & hexagonal & $90^{\circ}$ & $90^{\circ}$ & $120^{\circ}$ & 3,2522 & 3,2522 & 5,2095 \\
\hline
\end{tabular}

Tabel 1 menunjukkan perbandingan parameter kristal $\mathrm{ZnO}$ untuk setiap sampel. Sistem kristal yang terbentuk pada semua sampel adalah hexagonal dengan parameter kisi $\alpha=\beta=90^{\circ}$ dan $\gamma=120^{\circ}$ sedangkan nilai $a, b$, dan $c$ pada masing-masing sampel berbeda. Tabel 1 menunjukkan struktur kristal pada setiap sampel berbentuk wurtzite dengan $a=b=3,2 \AA$ dan $c$ $=5,2 \AA$. Pada $\mathrm{ZnO} 90$ nilai $a, b$, dan $c$ berbeda dari sampel lain akan tetapi tidak mempengaruhi struktur kristal dari nanopartikel $\mathrm{ZnO}$ yang terbentuk. 


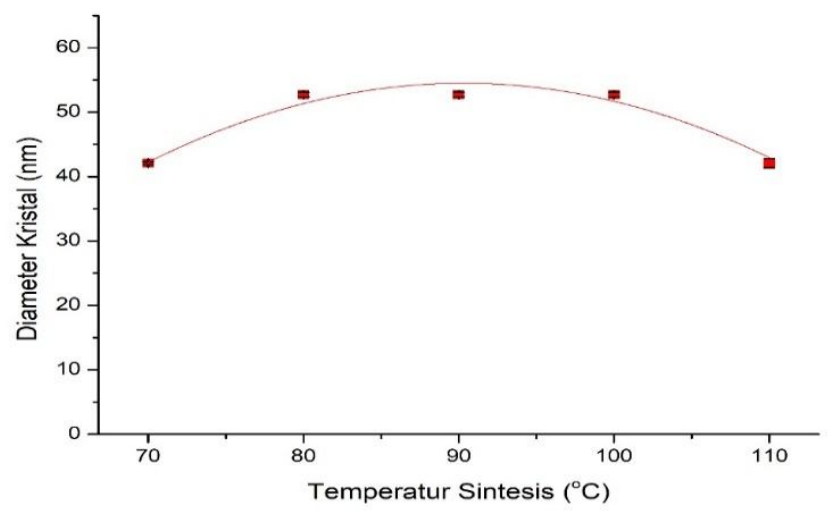

Gambar 5 Diagram suhu sintesis terhadap diameter kristal nanopartikel $\mathrm{ZnO}$ yang terbentuk

Gambar 5 menampilkan pengaruh suhu sintesis terhadap diameter kristal nanopartikel $\mathrm{ZnO}$ yang terbentuk. Diameter kristal $\mathrm{ZnO}$ naik ketika temperatur sintesis dinaikkan. Diatas suhu $100{ }^{\circ} \mathrm{C}$, diamater kristal kembali mengalami penurunan. Semakin tinggi temperatur, semakin kecil diameter kristal. Menurut Sholehah (2015), semakin tinggi temperatur sintesis, semakin kecil diameter kristal nanopartikel $\mathrm{ZnO}$. Pada temperatur $90{ }^{\circ} \mathrm{C}$ diameter kristal nanopartikel $\mathrm{ZnO}$ yang terbentuk lebih besar daripada sampel yang lain. Diameter kristal nanopartikel $\mathrm{ZnO}$ lebih kecil daripada diameter nanopartikel $\mathrm{ZnO}$, maka jenis kristal nanopartikel $\mathrm{ZnO}$ yang terbentuk berupa polikristal dimana perbandingan diameter nanopartikel rata-rata dengan diameter kristal rata-rata pada $\mathrm{ZnO}$ dengan temperatur $70{ }^{\circ} \mathrm{C}, 80{ }^{\circ} \mathrm{C}, 100{ }^{\circ} \mathrm{C}$, dan $110{ }^{\circ} \mathrm{C}$ sebesar dua dan pada temperatur $90{ }^{\circ} \mathrm{C}$ sebesar tiga.

\section{KESIMPULAN}

Temperatur sintesis mempengaruhi diameter nanopartikel $\mathrm{ZnO}$ yang terbentuk. Ukuran diameter nanopartikel $\mathrm{ZnO}$ yang terbentuk berfluktuasi terhadap temperatur sintesis dengan polinomial orde dua. Partikel $\mathrm{ZnO}$ dengan temperatur $80{ }^{\circ} \mathrm{C}$ yang terbentuk berupa nanorod dengan struktur kristal berbentuk hexagonal. Diameter kristal nanopartikel $\mathrm{ZnO}$ dipengaruhi oleh temperatur sisntesis, ukuran diameter kristal $\mathrm{ZnO}$ yang terbentuk fluktuasi terhadap temperatur sintesis dengan polinomial orde dua. Diameter nanopartikel $\mathrm{ZnO}$ lebih besar dibanding diameter kristal, sehingga dapat disimpulkan bahwa partikel yang terbentuk adalah polykristal.

\section{DAFTAR PUSTAKA}

Abdullah, M., Pengantar Nanosains (Institut Teknologi Bandung (ITB), Bandung, 2009).

Yuwono, A. H., dan Dharma, H., Fabrikasi Nanorod Seng Oksida (ZnO) dengan Menggunakan Metode Sol-Gel dengan Variasi Konsentrasi Polyethylene Glycol dan Waktu Tunda Evaporasi Amonia, Majalah Metalurgi, hal. 101-108, 2011.

Romero, S.L., and Garcia-H, M., Photoluminescence and Structural Properties of $\mathrm{ZnO}$ Nanorods Growth by Assisted Hydrothermal Method, World Journal of Condensed Matter Physics, hal. 123-157, 2013.

Sholehah, A., "Sintesis Nanostruktur Seng Oksida $(\mathrm{ZnO})$ Berketeraturan Tinggi dengan Metode Kimiawi Basah Untuk Aplikasi Sel surya Tersensitasi Zat Pewarna", Disertasi, Universitas Indonesia, 2015.

Sirenden, A. H., "Sintesis Nanorods Seng Oksida (ZnO) Menggunakan Putih Telur Sebagai Biotemplate", Skripsi, Universitas Indonesia, 2012.

Stein, O. H., "Sintesis dan Karakterisasi Nanorod ZnO Hasil Proses Sol-Gel dan Hidrotermal Untuk Aplikasi Sel Surya Tersensitasi Zat Pewarna Organik", Skripsi, Universitas Indonesia, 2009. 